\title{
Molecular characterization of glucose-6-phosphate dehydrogenase deficiency in patients from the southern Brazilian city of Porto Alegre, RS
}

\author{
Simone M. de Castro ${ }^{1}$, Raquel Weber ${ }^{1},{\text { Úrsula } \text { Matte }^{2} \text { and Roberto Giugliani }}^{3}$ \\ ${ }^{1}$ Faculdade de Farmácia, Universidade Federal do Rio Grande do Sul, Porto Alegre, RS, Brazil. \\ ${ }^{2}$ Centro de Terapia Gênica, Hospital das Clínicas de Porto Alegre, \\ Universidade Federal do Rio Grande do Sul, Porto Alegre, RS, Brazil. \\ ${ }^{3}$ Serviço de Genética Médica, Hospital de Clínicas de Porto Alegre, \\ Universidade Federal do Rio Grande do Sul, Porto Alegre, RS, Brazil.
}

\begin{abstract}
Glucose-6-phosphate dehydrogenase (G6PDH; EC 1.1.1.49) deficiency is one of the most common human enzymopathies throughout the world. Although most affected individuals are asymptomatic, there is a risk of neonatal jaundice and acute hemolytic anemia which can be triggered by infection, some pharmaceuticals and, in older individuals, eating fava beans. We characterized the molecular basis of G6PDH deficiency in a sample of 348 adults from Porto Alegre (population about 1.5 million), the capital of the southernmost Brazilian state of Rio Grande do Sul. Genomic DNA was extracted from peripheral blood leukocytes. We studied the three G6PDH mutations that appear to be the most frequent in Southern Brazil, the G202A and A376G A minus (A-) variants and the C563T Mediterranean (Med) variant. From July 2004 to October 2005, 348 patients (162 Females plus 186 males, age range 0 to 82 years) from Porto Alegre were referred to our laboratory for G6PDH analysis, $36(9.7 \%)$ of which showed deficient G6PDH activity. These 36 patients and 34 randomly-selected non-deficient control individuals were submitted to molecular analysis which revealed a predominance of G6PDH A- allele among the deficient patients. The prevalence of the G6PDH A- variant agrees with its distribution among the ethnic groups that colonized RS, especially those of African, Portuguese, Spanish, and Italian origin.
\end{abstract}

Key words: G6PDH deficiency, Hemolytic anemia, pentose pathway.

Received: February 3, 2006; Accepted: July 4, 2006.

Glucose-6-phosphate dehydrogenase (G6PDH; EC 1.1.1.49) is expressed in all tissues, where it catalyses the first step in the pentose phosphate pathway (PPP) and produces NADPH which serves as an electron donor in reductive biosynthesis. Since red blood cells lack mitochondria, the PPP is their only source of NADPH and crucial for their protection from oxidative stress (Mehta et al., 2000).

Deficiency in G6PDH is one of the most common human enzymopathies throughout the world. Although most affected individuals are asymptomatic, there is a risk of neonatal jaundice and acute hemolytic anemia, triggered by infection, the ingestion of certain pharmaceuticals and, in weaned individuals, fava beans (favism) (Beutler, 1994). The disorder occurs most frequently in individuals of Meditarrenean, African and Asian origin, with an incidence

Send correspondence to Simone Martins de Castro. Faculdade de Farmácia, Universidade Federal do Rio Grande do Sul, Av. Ipiranga 2752, 90610-000 Porto Alegre, RS, Brazil. E-mail: scastro@ adufrgs.ufrgs.br. as high as $20 \%$ in some populations. Previous reports have shown that in several regions of Brazil the prevalence of G6PDH deficiency is around 10\% among males of African origin and between $1 \%$ and $6 \%$ in males of European descendent (Azevedo and Azevedo, 1974; Garlip and Ramalho, 1988; Weimer et al., 1993; Saad et al., 1997; Weimer et al., 1998). Inheritance of G6PDH shows a characteristic X-linked pattern and the gene has been mapped to chromosome Xq28, with males being more prone to developing symptoms of G6PDH deficiency disorder. The G6PDH gene is comprised of 13 exons spanning nearly 20 $\mathrm{kb}$ and encoding 515 amino acids with a GC-rich promoter typical of many housekeeping genes (Beutler, 1994; Mehta et al., 2000).

To date, more than 140 different molecular abnormalities and 400 biochemical variants have been described in G6PDH-deficient individuals, with a considerable variation in the defects among various racial groups (Luzzato and Mehta, 1995; Beutler and Vulliamy, 2002, Human Genetics Database). The vast majority of affected individuals 
are asymptomatic. Almost all mutations of G6PDH affect the coding sequence of the gene. The vast majority are single base substitutions leading to amino acid change. A few of these occur as a second mutation, most frequently in combination with the polymorphic mutation that distinguishes the non-deficient variant G6PDH A from the wild-type enzyme G6PDH B. The only deletions seen in the coding sequence are small and in-frame. The absence of large deletions or frameshift mutations suggests that a total lack of G6PDH is incompatible with life (Mehta et al., 2000).

In the southernmost Brazilian state of Rio Grande do Sul (RS) estimates of the frequency of G6PDH deficiency among both sexes range from $3 \%$ to $8 \%$ (Weimer et al., 1981; Neto et al., 1999) and several variant forms of G6PDH-deficiency have been reported (Hutz et al., 1977; Weimer et al., 1993; Saad et al., 1997; Weimer et al., 1998; Compri et al., 2000), the most common being the G6PDH A minus (A-) variant (Saad et al., 1997; Compri et al., 2000) which results in a residual enzymatic activity of between $85 \%$ and $95 \%$ as compared to normal donors (Kay et al., 1992). In this study, we have characterized the molecular basis of G6PDH deficiency in a sample from Porto Alegre, Brazil.

This study was carried out from July 2004 to October 2005 using blood samples collected from 348 patients from Porto Alegre (the capital city (population about 1.5 million) of Rio Grande do Sul) who were under investigation for G6PDH deficiency and had been referred to the Medical Genetics Service at Porto Alegre Clinical Hospital (Hospital das Clínicas de Porto Alegre - HCPA) for G6PDH analysis because they had reported of acute hemolytic anemia crises, a family history of G6PDH deficiency or had shown occasional reduced enzyme activity. Informed consent form was signed by all the patients and the study was approved by the Medical Ethics Committee of HCPA.

The Interscientific Neolisa G6PDH Kit (Interscientific Corporation, Hollywood, FL, USA) was used for the quantitative measurement of G6PDH activity as previously described (Reclos et al., 2000). Of the 348 patients (162 Females plus 186 males, age range 0 to 82 years)examined the enzyme assay detected 36 patients $(21$ male and 15 female, $9.7 \%$ of the total sample) who had G6PDH levels lower than 11.5 units per gram of hemoglobin $\left(\mathrm{U} \mathrm{g}^{-1} \mathrm{Hb}\right)($ Table 1$)$. These 36 patients plus $34(\mathrm{n}=70)$ randomly-selected non-deficient control individuals were submitted to molecular analysis.

Genomic DNA was extracted from peripheral blood leukocytes of the 70 individuals as previously described by Miller et al., (1988). We studied the three mutations that appear to be the most frequent in Southern Brazil, the G202A and $\mathrm{A} 376 \mathrm{G} \mathrm{A}-$ mutations and the C563T Med mutation. The coding region of the G6PDH gene encompassing the A- and Mediterranean mutations were analyzed using the polymerase chain reaction (PCR) and primer sets appropri-
Table 1 - Glucose-6-phosphate dehydrogenase (G6PDH) activity of 15 female and 21 male $(n=36)$ patients from the southern Brazilian city of Porto Alegre. For both sexes the table is ordered by G6PDH levels, levels lower than $11.5 \mathrm{U} \mathrm{g}^{-1}$ of hemoglobin $(\mathrm{Hb})$ indicate deficiency.

\begin{tabular}{|c|c|c|c|}
\hline Patient code & $\begin{array}{l}\text { G6PDH activity } \\
\left(\mathrm{U} \mathrm{g}^{-1} \mathrm{Hb}\right)\end{array}$ & Mutation A376G & Mutation G202A \\
\hline \multicolumn{4}{|l|}{ Female } \\
\hline 1 & 3.4 & Homozygous & Homozygous \\
\hline 2 & 5.6 & Heterozygous & Heterozygous \\
\hline 3 & 5.7 & Homozygous & Homozygous \\
\hline 4 & 5.8 & Homozygous & Homozygous \\
\hline 5 & 5.9 & Heterozygous & Heterozygous \\
\hline 6 & 6.5 & Negative & Negative \\
\hline 7 & 7 & Homozygous & Homozygous \\
\hline 8 & 7.2 & Heterozygous & Heterozygous \\
\hline 9 & 8.9 & Heterozygous & Heterozygous \\
\hline 10 & 9.7 & Heterozygous & Heterozygous \\
\hline 11 & 10.3 & Heterozygous & Heterozygous \\
\hline 12 & 10.4 & Heterozygous & Heterozygous \\
\hline 13 & 11.4 & Heterozygous & Heterozygous \\
\hline 14 & 11.4 & Heterozygous & Heterozygous \\
\hline 15 & 10.2 & Heterozygous & Heterozygous \\
\hline \multicolumn{4}{|l|}{ Male } \\
\hline 1 & 2.2 & Hemizygous & Hemizygous \\
\hline 2 & 2.7 & Hemizygous & Hemizygous \\
\hline 3 & 2.7 & Hemizygous & Hemizygous \\
\hline 4 & 2.8 & Hemizygous & Hemizygous \\
\hline 5 & 2.9 & Hemizygous & Hemizygous \\
\hline 6 & 3.2 & Hemizygous & Hemizygous \\
\hline 7 & 3.4 & Hemizygous & Hemizygous \\
\hline 8 & 3.4 & Negative & Negative \\
\hline 9 & 3.8 & Hemizygous & Hemizygous \\
\hline 10 & 4.1 & Hemizygous & Hemizygous \\
\hline 11 & 4.3 & Hemizygous & Hemizygous \\
\hline 12 & 4.5 & Hemizygous & Hemizygous \\
\hline 13 & 4.7 & Hemizygous & Hemizygous \\
\hline 14 & 4.7 & Hemizygous & Hemizygous \\
\hline 15 & 4.9 & Hemizygous & Hemizygous \\
\hline 16 & 5 & Hemizygous & Hemizygous \\
\hline 17 & 5.7 & Hemizygous & Hemizygous \\
\hline 18 & 6 & Hemizygous & Hemizygous \\
\hline 19 & 6.1 & Hemizygous & Hemizygous \\
\hline 20 & 6.3 & Hemizygous & Hemizygous \\
\hline 21 & 9.8 & Hemizygous & Hemizygous \\
\hline
\end{tabular}

ate for the amplification of exons 6,4 and 5 as previous described (Vulliamy et al., 1991; Cittadella et al., 1997; Bouanga et al., 1998).

Mutation screening of the 70 individuals revealed that a high proportion of the 36 deficient patients were positive 
for the G6PDH A-variant (94.4\%). However, only four females were homozygous for G6PDH A- (females 1, 3, 4 and 7 in Table 1) and none of the non-deficient controls were positive for any of the mutations investigated. One female (Female 6 in Table 1, G6PDH $=6.5 \mathrm{U} \mathrm{g}^{-1} \mathrm{Hb}$ ) and one male (Male 8 in Table 1, G6PDH $=3.4 \mathrm{U} \mathrm{g}^{-1} \mathrm{Hb}$ ) patient were G6PDH deficient but negative for the three mutations analyzed.

Other studies have characterized the relatively high variability of G6PDH among Brazilian populations. As expected, these studies reported the same alleles (G6PDH B, G6PDH A, G6PDH A- and G6PDH Med) commonly found in populations of European and African descent (Saad et al., 1997; Weimer et al., 1998; Compri et al., 2000). Several biochemical variants have been described in southern Brazil, some of which have been characterized at the molecular level (Weimer et al., 1998; Weimer et al., 1993, Hutz et al., 1977). However, the population in the state of Rio Grande do Sul is mainly triallelic regarding G6PDH with a predominance of the wild type (G6PDH B) enzyme, followed by the G6PDH A and G6PDH A- alleles which are of African-origin.

Using molecular and biochemical techniques, we could characterize G6PDH deficiency in a sample from Porto Alegre as being mainly due to the G6PDH A- allele G202A or A376G mutations. Although we screened only a small number of cases, our results are in accordance with the published data (Saad et al., 1997; Weimer et al., 1998; Compri et al., 2000), showing the homogeneous distribution of the G6PDH A- mutation in Brazil.

Weimer et al. (1993) and Luzzato and Mehta (1995) suggest that the G6PDH A- variant is not restricted to individuals of African descent but is frequent in populations from southern Italy, Spain, Portugal and the Arabian Peninsula. Therefore, the prevalence of this variant is in agreement to its distribution among the ethnic groups (Africans, Portuguese, Spaniards and Italians) that colonized Rio Grande do Sul (Pesavento, 1993).

The Mediterranean variant has also been reported in samples from Rio Grande do Sul (Weimer et al., 1998). Nevertheless, in our study there was no individual with the C563T mutation. However, it is important to note that the Italian immigrants to Rio Grande do Sul were almost exclusively from the Pó Valley and other regions of Northern Italy such as Vêneto, Vicenza, Treviso, Verona and Beluno (De Boni and Costa, 1984) where G6PDH deficiency is significantly less frequent than in Southern Italy.

In our study, two deficient patients were negative for the mutations screened. It is possible that they bear other mutations not screened for or as yet uncharacterized. Several rare variants have been described in Rio Grand do Sul, such as G6PDH S. Borja, Anaheim, Guaíba, Minas Gerais, Porto Alegre, Seattle and Farroupilha. For many of them the molecular defect has not been described but their elec- trophoretic and biochemical characteristics place them apart (Hutz et al., 1977; Weimer et al., 1998).

Since more than 140 G6PDH variants have been described (Beutler and Vulliamy, 2002) a complete analysis of all mutations would be expensive and screening of common mutations is more effective, as shown by the fact that $94.4 \%$ of deficient patients were genotyped in this study by analyzing the G6PDH A- and Med variants.

Aknowledge of the local G6PDH mutation frequency is also important for analysis of females because the prevalence of G-6-PD deficiency in females has been infrequently studied (Reclos et al., 2003). Enzyme assay may not always give a definitive answer, regarding carrier status in females (Beutler, 2001) but molecular analysis, although not suitable for mass screening, is an accurate method by which to assess the G6PDH genetic status of females (Mehta et al., 2000; Lin et al., 2005). In our study, 10 out of $15(66.7 \%)$ of females were found to be carriers. Even though molecular analysis alone is insufficient to assess the real risk of a women carrying a deficient G6PDH gene it is helpful for genetic counseling and the better management of disease symptoms.

\section{Acknowledgments}

This work was supported by the Brazilian commercial company Empresa Intercientífica, São Paulo, Brazil and the Brazilian Federal Agency Fundo de Incentivo a Pesquisa e Eventos (FIPE-HCPA), Porto Alegre-RS, Brazil.

\section{References}

Azevedo ES and Azevedo TFS (1974) Glucose-6-phosphate dehydrogenase deficiency and neonatal jaundice in Bahia, Brazil. Cienc Cult 26:1044-47.

Beutler E (1994) G6PD deficiency. Blood 84:3613-36.

Beutler E (2001) Discrepancies between genotype and phenotype in hematology: An important frontier. Blood 98:2597-602.

Beutler E and Vulliamy TJ (2002) Hematologically important mutations: Glucose-6-phosphate dehydrogenase. Blood Cells Mol Dis 28:93-103.

Bouanga JC, Mouele R, Prehu C, Wajcman H, Feingold J and Galacteros F (1998) Glucose-6-phosphate dehydrogenase deficiency and homozygous sickle cell disease in Congo. Hum Hered 48:192-7.

Compri MB, Saad ST and Ramalho AS (2000) Genetico-epidemiological and molecular investigation of G-6-PD deficiency in a Brazilian community. Cad Saude Publica 16:335-42.

Cittadella R, Civitelli D, Manna I, Azzia N, Di Cataldo A, Schiliro G and Brancati C (1997) Genetic heterogeneity of glucose-6-phosphate dehydrogenase deficiency in south-east Sicily. Ann Hum Genet 61:229-34.

De Boni LA and Costa R (1984) Os Italianos do Rio Grande do Sul. 3rd edition. Universidade de Caxias and Correio Riograndense, Caxias do Sul, 244 pp. 
Garlipp CR and Ramalho AS (1988) Aspectos clínicos e laboratoriais da deficiência de G-6-PDH em recém-nascidos brasileiros. Rev Bras Genet 11:3 717-728.

Human Genetics Database, http://www.hgmd.cf.ac.uk/hgmdO. html, 2/17/2006).

Hutz MH, Yoshida A and Salzano FM (1977) Three rare G-6-PD variants from Porto Alegre, Brazil. Hum Genet 39:191-7.

Kay AC, Kuhl W, Prchal J and Beutler E (1992) The origin of glucose-6-phosphate-dehydrogenase (G6PD) polymorphisms in African-Americans. Am J Hum Genet 50:394-8.

Lin Z, Fontaine JM, Freer DE and Naylor EW (2005) Alternative DNA-based newborn screening for glucose-6-phosphate dehydrogenase deficiency. Mol Genet Metab 86:212-9.

Luzzato L and Mehta A (1995) Glucose-6-phosphate dehydrogenase deficiency. In: Scriver CR, Beaudet AL, Sly WS and Valle D (eds) The Metabolic and Molecular Basis of Inherited Disease. McGraw-Hill, New York, pp 3367-3398.

Mehta A, Mason PJ and Vulliamy TJ (2000) Glucose-6-phosphate dehydrogenase deficiency. Best Pract Res Clin Haematol 13:21-38.

Miller SA, Dykes DD and Polesky HF (1988) A simple salting out procedure for extracting DNA from human nucleated cells. Nucleic Acids Res 16:1215.

Neto EC, Portal L and Ferreira LF (1999) G6PD deficiency in an unselected Brazilian population. Southeast Asian J Trop Med Public Health 30:87.

Pesavento SJ (1993) Gaúcho: A integração do múltiplo. In: Coutinho C (eds) Rio Grande do Sul: Continente Múltiplo. Editora Gráfica Metrópole, Porto Alegre, 160 pp.
Reclos GJ, Hatzidakis CJ and Schulpis KH (2000) Glucose6-phosphate dehydrogenase deficiency neonatal screening: Preliminary evidence that a high percentage of partially deficient female neonate are missed during routine screening. $\mathrm{J}$ Med Screen 7:46-51.

Reclos GJ, Schulpis KH, Gavrili S and Vlachos G (2003) Evaluation of glucose-6-phosphate dehydrogenase activity in two different ethnic groups using a kit employing the haemoglobin normalization procedure. Clin Biochem 36:393-5.

Saad ST, Salles TS, Carvalho MH and Costa FF (1997) Molecular characterization of glucose-6-phosphate dehydrogenase deficiency in Brazil. Hum Hered 47:17-21.

Vulliamy TJ, Othman A, Town M, Nathwani A, Falusi AG, Mason PJ and Luzzatto L (1991) Polymorphic sites in the African population detected by sequence analysis of the glucose-6-phosphate dehydrogenase gene outline the evolution of the variants A and A-. Proc Natl Acad Sci USA 88:8568-71.

Weimer TA, Salzano FM and Hutz MH (1981) Erythrocyte Isozymes and hemoglobin types in a Sounthern Brazilian Population. J HumEvol 10:319-328.

Weimer TA, Salzano FM, Westwood B and Beutler E (1993) Molecular characterization of glucose-6-phosphate dehydrogenase variants from Brazil. Hum Biol 65:41-7.

Weimer TA, Salzano FM, Westwood B and Beutler E (1998) G6PD variants in three South American ethnic groups: Population distribution and description of two new mutations. Hum Hered 48:92-6.

Associate Editor: Francisco Mauro Salzano 